\title{
Tailoring the mechanical and thermal properties of dicyclopentadiene polyHIPEs with the use of a comonomer
}

\author{
E. H. Mert ${ }^{1 *}$, C. Slugovc ${ }^{2}$, P. Krajnc ${ }^{3}$ \\ ${ }^{1}$ Yalova University, Faculty of Engineering, Polymer Engineering Department, 77100 Yalova, Turkey \\ ${ }^{2}$ Graz University of Technology, Institute for Chemistry and Technology of Materials, Stremayrgasse 9, A-8010 Graz, \\ Austria \\ ${ }^{3}$ University of Maribor, Faculty of Chemistry and Chemical Engineering, PolyOrgLab, Smetanova 17, Maribor, Slovenia
}

Received 30 June 2014; accepted in revised form 12 October 2014

\begin{abstract}
The effect of adding a comonomer to dicyclopentadiene in high internal phase emulsions (HIPEs) on the properties of ring-opening metathesis polymerisation (ROMP) derived polyHIPEs has been investigated. With this aim, dicylopentadiene was copolymerised with norbornene in surfactant stabilized high internal phase emulsions. Morphological, mechanical and thermal properties of the resulting materials were investigated with regard to the monomer ratio. The interconnected pore structure was observed for the resulting poly(dicylopentadiene-co-norbornene) polyHIPEs. Furthermore, the new polyHIPE copolymers were found to have an improved thermal stability compared to the poly(dicylopentadiene) homopolymer.
\end{abstract}

Keywords: mechanical properties, emulsion templating, polyHIPE, dicyclopentadiene, norbornene

\section{Introduction}

Emulsion templating is an effective method to prepare open porous polymers with well-defined morphology and properties such as low density, high porosity and interconnected pore structure. In recent years, microcellular polymers obtained from high internal phase emulsions (HIPEs) have attracted considerable attention [1-4]. A HIPE is an emulsion with an internal phase volume ratio greater than $74 \%$ of the total emulsion volume [5-8], although some definitions refer to HIPEs at lower internal phase ratios [9]. Polymerisation of the HIPE continuous phase and the subsequent removal of the dispersed phase leads to the formation of a monolithic porous polymer, usually termed a polyHIPE. The majority of reports describe polyHIPE preparation from the radical polymerisation of hydrophobic monomers; the most widely studied monomer sys- tem being styrene and divinylbenzene (DVB) [10, 11]. However, in order to expand the applications of polyHIPEs, a variety of more hydrophilic monomers have been studied including; 4-vinylbenzene chloride (VBC) [12-14], 4-nitrophenyl acrylate (NPA) [15], 2-hydroxyethyl methacrylate (HEMA) [16], acryl amide (AAm) [17], glycidyl methacrylate (GMA) and ethylene glycol dimethacrylate (EGDMA) [18-20]. In recent years, the preparation of polyHIPEs via oil-in-water $(\mathrm{o} / \mathrm{w})$ templates has attracted attention despite the difficulties in achieving a stable emulsion [1]. For instance poly(acrylic acid) polyHIPEs have been prepared by Krajnc et al. [21] from an o/w HIPE consisting of acrylic acid. More recently, Pulko and Krajc [4] succeeded to prepare hierarchically porous functional polyHIPEs from acryl amide (AAm) by using water soluble surfactants. While the majority of polyHIPEs are

\footnotetext{
${ }^{*}$ Corresponding author, e-mail: hmert@yalova.edu.tr

(C) BME-PT
} 
produced from radical chain growth polymerisations there are examples of step growth polymerisation as demonstrated by Lovelady et al. [22], Caldwell et al. [23] and Sergent et al. [24] who have used the fast kinetics of thiol-ene reaction to rapidly build the polymer network via a step growth mechanism. This was also successfully utilized for macro structuring of polyHIPEs via layer-by-layer photopolymerisation $[25,26]$. Moreover, the use of ring-opening metathesis reactions (ROMP) has also been successfully applied for the preparation of polyHIPEs [27-29]. Cyclic monomers, such as dicyclopentadiene (DCPD) were used and a one-pot procedure for the further functionalization of the polyHIPEs via the residual double bonds by thiol-ene reaction was developed [29, 30]. Recently, a polyHIPE membrane produced by ROMP of DCPD and norbornene has been utilised as a separator in Li-ion batteries [31] and in another study macroporous polyolefin membranes were prepared by using the same approach [32].

PolyHIPEs have been explored for a wide range of applications [31-39]. However, the poor mechanical strength originated from the highly porous and interconnected morphology is the major deficiency restricting the commercial applications. In the last decade, as well as a few studies have tried to address this issue, the poor mechanical properties of polyHIPEs are still required to be improved [40-42].

So far, in order to increase the mechanical strength of polyHIPEs several methods such as changing the polymerisable monomomer(s) and cross-linker comonomer, introducing a suitable reinforcement into the continuous phase or increasing the foam density have been used by scientists. However, increasing the foam density is not preferred since most of the applications of these materials required low density [39]. Within this context, Wu et al. [43] reported the preparation of nanoparticle reinforced polyHIPEs with reduced brittleness and chalkiness by using a stress-reducing cross-linker. More recently, Ikem et al. [44] synthesised polyHIPEs with increased compressive modulus and compressive strength from titania-particle-stabilized emulsion templates. Moreover, open porous architectures based on polyDCPD via ROMP with very favourable mechanical resilience and the highest $E$-moduli of polyHIPE materials of the respective porosity reported was demonstrated [29, 30, 41, 42].
Herein, the effect of the presence of a comonomer in the polymer matrix on the morphological features, mechanical strength and thermal stability of the polyHIPEs based on poly(dicylopentadiene) (polyDCPD) have been investigated. With this intent polyHIPEs have been prepared by incorporating various amounts of norbornene (NBE) into the polymer matrix. Moreover, ring-opening metathesis polymerisation (ROMP) has been used in order to accomplish an unsaturated polymer chain for further postfunctionalization applications. The change of the above mentioned properties with the NBE amount is discussed.

\section{Experimental section}

\subsection{Materials}

Dicyclopentadiene (Aldrich, DCPD), norbornene (Merck, NBE), Pluronic PEL121 (poly(ethylene glycol)-block-poly(propylene glycol)-block-poly (ethylene glycol) copolymer) (Aldrich), Toluene (Carlo Erba) were used without further purification. $\mathrm{M} 2$ ( $\left(\mathrm{H}_{2} \mathrm{IMes}\right)\left(\mathrm{PCy}_{3}\right) \mathrm{Cl}_{2} \mathrm{Ru}$ (3-phenyl-indenylid-1ene) with $\mathrm{H}_{2} \mathrm{IMes}=\mathrm{N}, \mathrm{N}$-bis(mesityl)4,5-dihydroimidazol-2-yl, $\mathrm{PCy}_{3}=$ tricyclohexylphosphine) was obtained from UMICORE.

\subsection{PolyHIPE Preparation}

PolyHIPE samples were prepared from DCPD and NBE monomer mixtures. The example given here is for poly(DCPD-co-NBE) polymer of 90/10 (molar) ratio of DCPD/NBE, $80 \mathrm{vol} \%$ porosity, $5 \mathrm{vol} \%$ of surfactant and $0.015 \mathrm{~mol} \%$ of initiator. These values were changed by altering the DCPD to NBE ratio between 100/0 and 10/90 (molar). DCPD (49.5 mmol, $6.64 \mathrm{~mL}), \mathrm{NBE}(5.5 \mathrm{mmol}, 0.61 \mathrm{~mL})$ and Pluronic L121 $(0.36 \mathrm{~mL})$ were added to a $250 \mathrm{~mL}$ two-necked round bottom flask. The mixture was stirred at approx. $400 \mathrm{rpm}$ with an overhead stirrer. The aqueous phase composed of deionised water $(28.9 \mathrm{~mL})$ was added drop-wise with constant stirring. Once the aqueous phase was added, the mixture was stirred for further $1 \mathrm{~h}$ followed by the addition of the initiator (M2) (0.015 mol\% with regards to monomer mixture) (see Figure 1). Afterwards, the emulsion was transferred to a polyethylene mould and cured at $80^{\circ} \mathrm{C}$ for $5 \mathrm{~h}$. The resulting polyHIPE was purified via Soxhlet extraction (ethanol, for $24 \mathrm{~h}$ ) and dried in vacuum at room temperature. 


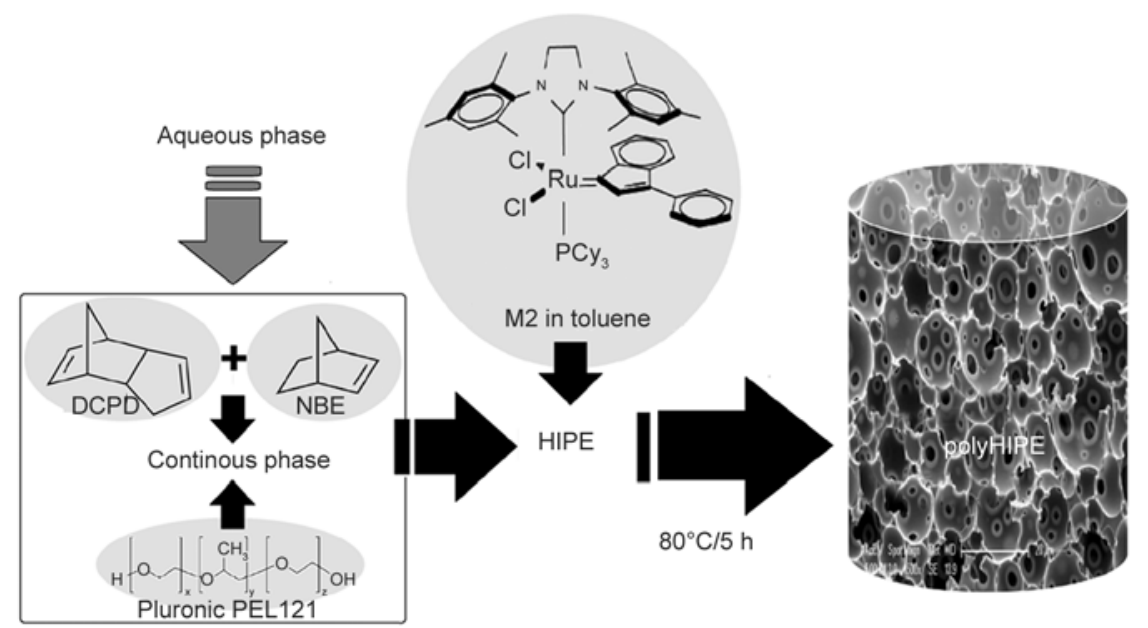

Figure 1. Preparation of poly(DCPD-co-NBE) polyHIPEs

\subsection{Characterisation}

The morphology of the resulting polyHIPEs was observed by scanning electron microscopy (SEM) using ESEM-FEG and EDAX Philips XL-30 microscope (Philips, Eindhoven, The Netherlands). As the resulting materials were too though and hard to break or cut, the SEM images were taken from the polymer pieces obtained by crushing the polyHIPEs in liquid nitrogen. In each measurement polyHIPE pieces were mounted on a copper stub and a thin layer of gold was sputtered on the samples prior to analysis. Average cell diameters and interconnecting pore diameters were measured from SEM images. Over 50 measurements were taken from each SEM image and the average value was corrected with a correction factor $\left(2 / 3^{1 / 2}\right)$ to account for irregular cutting of the samples [45].

Specific surface areas and cumulative pore volumes were measured at Central Laboratory of the Middle East Technical University (Ankara, Turkey) with Quantachrome's Autosorb-6B Surface Area and Pore Size Analyzer (Quantachrome GmbH \& Co. $\mathrm{KG}$, Germany) by applying the Brunauer-EmmetTeller (BET) molecular adsorption method. Prior to analysis, samples were degassed for $24 \mathrm{~h}$ at room temperature.

Mechanical strengths of the polyHIPEs were measured by performing uniaxial compression experiment with a Zwick/Roell Z020 Universal Testing Machine (Zwick GmbH \& Co.KG, Germany) equipped with a $10 \mathrm{kN}$ load cell. Compression tests were carried out according to the industrial standard ASTM D1621-2004. For each polyHIPE sample five specimen, which were $25 \mathrm{~mm}$ in diameter and $10 \mathrm{~mm}$ high, were tested at a compression rate of
$1.3 \mathrm{~mm} / \mathrm{min}$. The compression modulus and compressive strength were obtained from the original output of the instrument.

Thermogravimetric analysis (TGA) of the polyHIPEs were performed on a Seiko TG/DTA 6300 thermal analysis system instrument (Seiko Instruments Inc., Tokyo, Japan) under nitrogen flow with a heating rate of $10^{\circ} \mathrm{C} / \mathrm{min}$. The differential scanning calorimeter (DSC) measurements were performed on a Seiko DSC 7020 calorimeter (Seiko Instruments Inc., Tokyo, Japan) to measure glass transition temperatures of the samples by using instrument at a heating rate of $10^{\circ} \mathrm{C} / \mathrm{min}$. During DSC measurements, two heating and one cooling curves were recorded for each sample in a temperature range from 10 to $300^{\circ} \mathrm{C}$ and the heat flow was measured.

\section{Results and discussion}

The advantages of using a cyclic monomer for polyHIPE preparation are already known from recent studies [27-30, 41, 42]. Particularly, polyHIPEs prepared by ROMP of DCPD are unique members of emulsion templated open-porous materials. The key feature of such materials is that they can be produced by crosslinking of the monomer through olefin metathesis without using an additional cross-linker. NBE was chosen as a comonomer because it does not bear a second cyclic double bond thus the overall material's crosslinking degree is reduced. However, changed polymer structure is expected to have an effect on the mechanical properties of the product while the emulsion templating procedure needs optimization due to changed formulation of the oil phase. On the other hand, it is also required to investigate the influence of comonomer incorpora- 
tion in order to understand the variability of the properties with the change of monomer composition. Herein, we focused on the determination of the alternation of morphological, thermal and mechanical properties of polyDCPD polyHIPEs in the presence of a comonomer (NBE).

For investigation of morphological, mechanical and thermal properties freshly prepared samples were used. Morphology of the resulting polyHIPEs was investigated by SEM and the SEM micrographs of the materials are presented in Figure 2. In all cases, addition of NBE eventuated with polymers having spherical cells interconnected with minor pores. Average cell diameters and pore sizes were calculated from SEM images by taking over 50 measurements and the results are presented in Table 1. There was no significant change in the size of interconnecting pores comparing neat polyDCPD with norbornene containing copolymers. The change of cavity diameters on the other hand, was more remarkable then the change in interconnected pore sizes. It was found that the addition of NBE increases the cavity diameters between 40 and 52\% depending on the NBE content of each copolymer sample (c.f. Table 1). This reflects the changed polarity of the oil phase and thus larger droplets are obtained during the emulsion preparation which yields the material with larger cavities. It has to be noted that the surfactant and the surfactant concentration was kept identical for all prepared samples (Pluronic L121; 5 vol $\%$ to oil phase). Additionally, specific surface area and cumulative pore volumes of the resulting materials were determined from nitrogen adsorption/desorption isotherms using the BET model and the results are presented in Table 1. Surface areas of the poly(DCPD/NBE) copolymers were decreased compared to the polyDCPD by approximately twofold, which is a consequence of the increase of cavity diameters.

Since oxidation is the major factor that causes the loss of mechanical strength it is important to investigate the mechanical features through unoxidized samples. Thus, mechanical tests were performed with freshly prepared, unoxidized polyHIPEs by applying compression tests under $10 \mathrm{kN}$ compressive load. Figure 3 demonstrates the standard force $[\mathrm{kPa}] /$ compression ratio [\%] curves obtained from the test samples, while the Table 2 summarizes the data obtained from the original software during the measurements. The similar curves having initial linear elasticity and plateau can be accepted as the evidence of classical foam behavior. At small strains, usually less than ca. $6 \%$, the behavior is linear elastic, with a slope equal to the compressive modulus. At higher loads the cavities of the foams begin to collapse and give a stress plateau. The characteristic maximum at the end of the linear elasticity region was used to determine the compressive strength.

The addition of NBE leads to increase of compression modulus and compressive strength. It was found that addition of $50 \mathrm{~mol} \%$ of NBE increases the compression modulus by ca. $55 \%$. However, when the ratio of NBE exceeded $50 \mathrm{~mol} \%$ the compression modulus decreased. It was found that, as compared to $\mathrm{P} 6$ the compression modulus of $\mathrm{P} 7$ decreased from 69.4 to $56.2 \mathrm{MPa}$. An increase in the NBE ratio from 60 to $90 \mathrm{~mol} \%$ resulted in an irregular decrease of the compression modulus for the P8, P9 and P10. Additionally, in accordance with the compressive modulus, sample P6 was found to have the maximum compressive strength. Finally, the compression modulus and compressive strength of $\mathrm{P} 10$ was found to comparable with P1.

Table 1. Morphological characterisation of polyDCPD homopolymer and poly(DCPD/NBE) copolymers.

\begin{tabular}{|c|c|c|c|c|c|c|}
\hline Sample & $\begin{array}{c}\text { DCPD } \\
{[\mathrm{mol} \%]}\end{array}$ & $\begin{array}{c}\text { NBE } \\
{[\mathrm{mol} \%]}\end{array}$ & $\begin{array}{c}\text { Surface area } \\
{\left[\mathrm{m}^{2} \cdot \mathrm{g}^{-1}\right]}\end{array}$ & $\begin{array}{c}\text { Cavity diameter } \\
{[\mu \mathrm{m}]}\end{array}$ & $\begin{array}{l}\text { Pore diameter } \\
\qquad[\mu \mathrm{m}]\end{array}$ & $\begin{array}{c}\mathbf{V}_{\mathbf{p}}{ }^{\mathbf{c}} \\
{\left[\mathrm{mL} \cdot \mathrm{g}^{-1}\right]}\end{array}$ \\
\hline P1 & 100 & 0 & $7.34 \pm 1.4$ & $6.48 \pm 0.2$ & $2.22 \pm 0.1$ & $5.30 \pm 2.4$ \\
\hline P2 & 90 & 10 & $4.67 \pm 0.3$ & $11.50 \pm 0.9$ & $2.20 \pm 0.1$ & $6.60 \pm 3.5$ \\
\hline P3 & 80 & 20 & $5.17 \pm 0.6$ & $12.81 \pm 1.1$ & $2.27 \pm 0.1$ & $6.90 \pm 2.6$ \\
\hline P4 & 70 & 30 & $5.80 \pm 0.2$ & $12.85 \pm 1.1$ & $2.27 \pm 0.1$ & $6.70 \pm 2.5$ \\
\hline P5 & 60 & 40 & $4.20 \pm 0.1$ & $13.38 \pm 1.3$ & $2.25 \pm 0.1$ & $6.70 \pm 2.0$ \\
\hline P6 & 50 & 50 & $5.56 \pm 1.6$ & $13.76 \pm 0.9$ & $2.45 \pm 0.1$ & $7.30 \pm 6.3$ \\
\hline P7 & 40 & 60 & $5.90 \pm 0.8$ & $12.87 \pm 1.1$ & $2.43 \pm 0.1$ & $7.30 \pm 2.2$ \\
\hline P8 & 30 & 70 & $3.87 \pm 0.1$ & $8.23 \pm 0.2$ & $2.36 \pm 0.1$ & $7.60 \pm 0.1$ \\
\hline P9 & 20 & 80 & $4.68 \pm 0.6$ & $10.12 \pm 0.6$ & $2.34 \pm 0.1$ & $7.20 \pm 1.9$ \\
\hline P10 & 10 & 90 & $4.18 \pm 0.1$ & $10.51 \pm 0.4$ & $2.45 \pm 0.1$ & $6.90 \pm 1.9$ \\
\hline
\end{tabular}



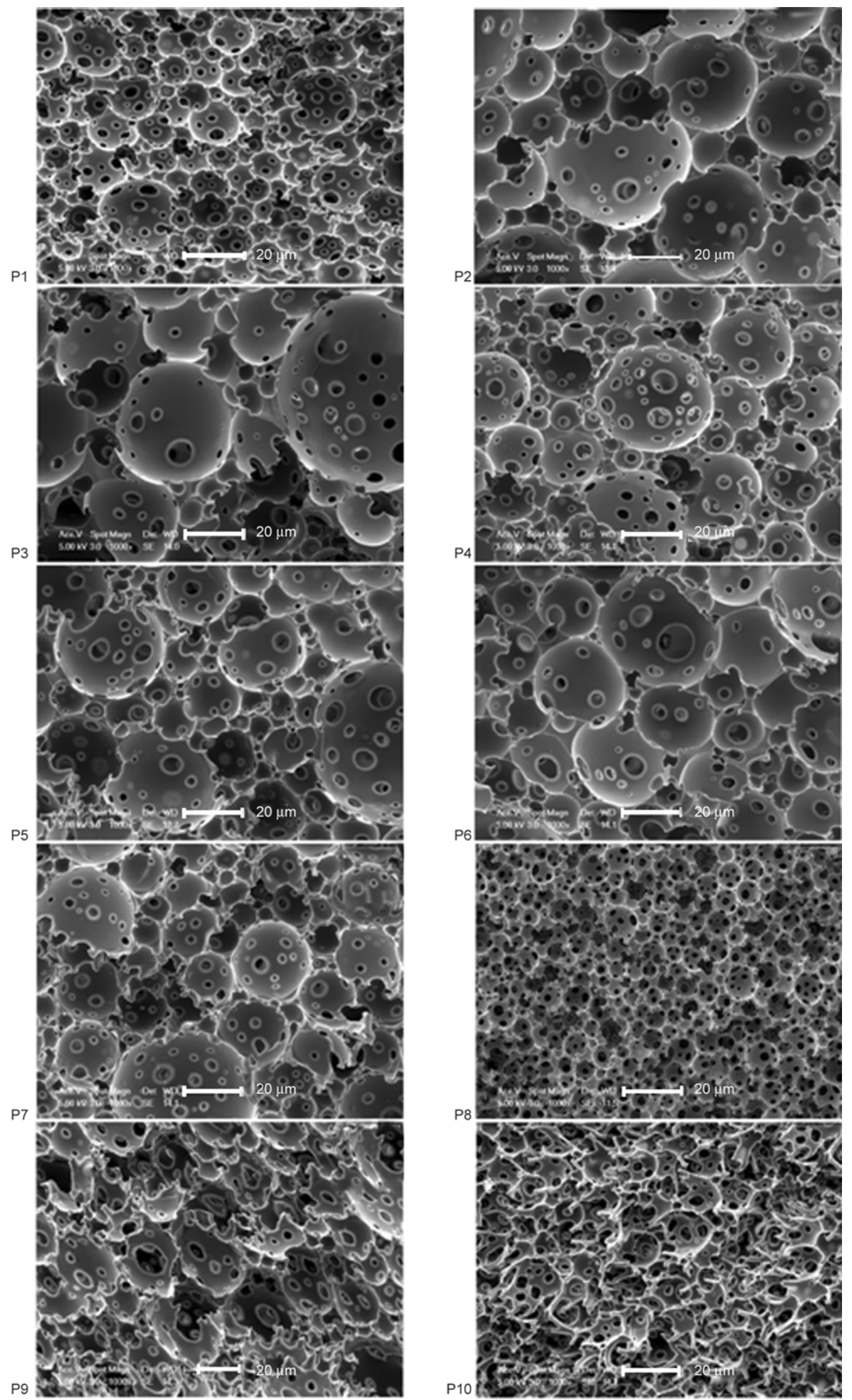

Figure 2. SEM images of the polyDCPD homopolymer (P1) and poly(DCPD/NBE) copolymers (P2-P10) 

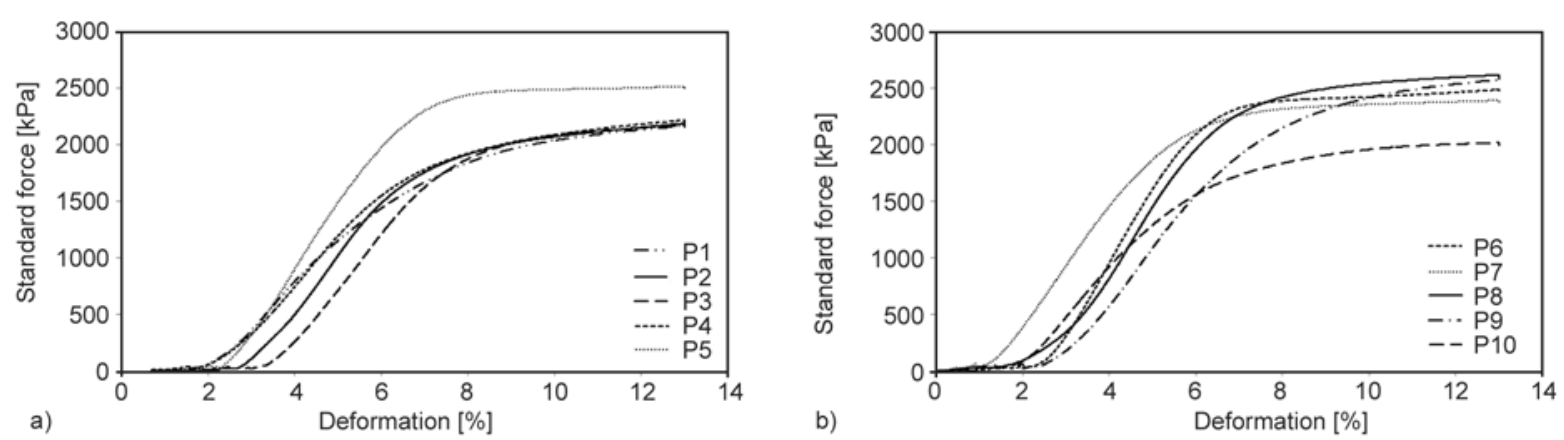

Figure 3. Mechanical characterization of polyDCPD homopolymer (P1) (a) and poly(DCPD/NBE) copolymers (P2-P10) $(a, b)$

Table 2. Mechanical and thermal characterization of polyDCPD homopolymer (P1) and poly(DCPD/NBE) copolymers (P2-P10)

\begin{tabular}{|c|c|c|c|c|c|c|c|c|}
\hline Sample & $\begin{array}{c}\mathbf{E}_{\mathrm{c}}^{\text {a) }} \\
{[\mathrm{MPa}]}\end{array}$ & $\begin{array}{c}\sigma_{M}{ }^{b)} \\
{[\mathrm{MPa}]}\end{array}$ & $\begin{array}{c}\mathbf{T}_{\mathrm{d} 5} \\
{\left[{ }^{\circ} \mathbf{C}\right]}\end{array}$ & $\begin{array}{l}\mathbf{T}_{\mathbf{d 1 0}} \\
{\left[{ }^{\circ} \mathbf{C}\right]}\end{array}$ & $\begin{array}{l}\mathbf{T}_{\mathbf{d 5 0}} \\
{\left[{ }^{\circ} \mathbf{C}\right]}\end{array}$ & $\begin{array}{c}V_{\max } \text { at } T_{\max } \\
{\left[\% \cdot \min ^{-1]} \text { at }\left[{ }^{\circ} \mathrm{C}\right]\right.}\end{array}$ & $\begin{array}{l}\text { Char } \\
{[w t \%]}\end{array}$ & $\begin{array}{r}\mathbf{T}_{\mathbf{g}} \\
{\left[{ }^{\circ} \mathbf{C}\right]}\end{array}$ \\
\hline P1 & 44.6 & 1.0 & 144.9 & 222.3 & 446.7 & 5.39 at 448.5 & 29.1 & - \\
\hline P2 & 50.7 & 1.5 & 274.8 & 372.5 & 458.7 & 11.67 at 467.3 & 15.5 & 188.2 \\
\hline P3 & 49.7 & 1.6 & 346.5 & 397.1 & 453.6 & 12.61 at 462.2 & 19.8 & 145.6 \\
\hline $\mathrm{P} 4$ & 46.6 & 1.4 & 346.4 & 394.6 & 461.8 & 13.19 at 465.7 & 17.0 & 130.6 \\
\hline P5 & 62.4 & 1.7 & 276.7 & 359.7 & 452.4 & 11.56 at 462.5 & 15.3 & 125.0 \\
\hline P6 & 69.4 & 1.8 & 278.1 & 367.5 & 453.5 & 13.10 at 457.4 & 11.3 & 111.4 \\
\hline P7 & 56.2 & 1.6 & 389.8 & 413.8 & 462.6 & 14.14 at 462.0 & 11.1 & 85.6 \\
\hline P8 & 65.2 & 1.8 & 309.6 & 387.8 & 454.3 & 13.98 at 456.0 & 5.6 & 70.2 \\
\hline P9 & 53.0 & 1.5 & 392.0 & 411.7 & 457.1 & 15.07 at 455.9 & 7.7 & 82.7 \\
\hline $\mathrm{P} 10$ & 46.4 & 1.1 & 393.9 & 415.4 & 452.9 & 16.90 at 460.9 & 0.6 & 61.0 \\
\hline
\end{tabular}

${ }^{\text {a) }} E_{\mathrm{c}}$ : compression modulus; ${ }^{\text {b) }} \sigma_{\mathrm{M}}$ : compressive strength

Thermal stability of polyDCPD homopolymer and poly(DCPD/NBE) copolymers were investigated by thermal gravimetric analysis (TGA). The curves obtained from TGA are presented in Figure 4 and Figure 5. Table 2, on the other hand summarizes the decomposition temperatures at 5,10,50\% weight loss $\left(T_{\mathrm{d} 5}, T_{\mathrm{d} 10}, T_{\mathrm{d} 50}\right)$, maximum rate of decomposition $\left(V_{\max }\right)$, temperature of maximum rate of decomposition $\left(T_{\max }\right)$ and residual char at $550^{\circ} \mathrm{C}$. As can be seen from Figure 4, polyDCPD homopolymer ( $\mathrm{P} 1)$ shows three stage decomposition and a continuous mass loss up to c.a. $500^{\circ} \mathrm{C}$. The mass

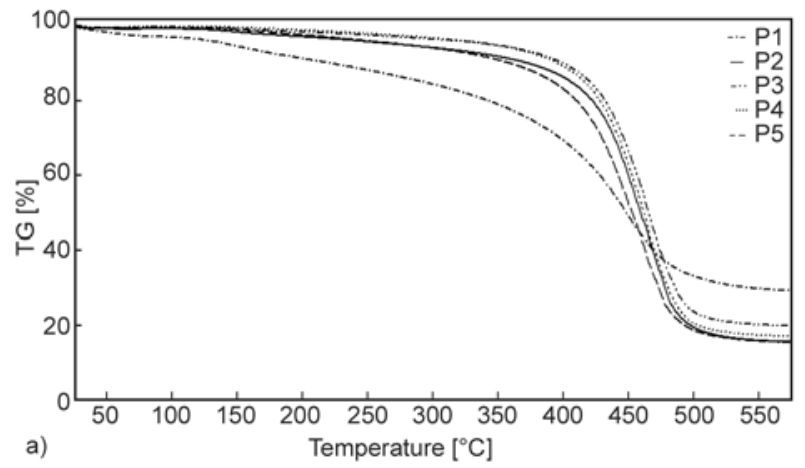

loss at $60^{\circ} \mathrm{C}$ can be explained by the water trapped within the cavities. On the other hand, polyDCPD homopolymer (P1) starts to lose mass slightly at $150^{\circ} \mathrm{C}$ and then continuous degradation begins. The largest mass loss occurred between 400 and $475^{\circ} \mathrm{C}$. In the case of copolymers (P2 to P10), the slight mass loss starts above $150^{\circ} \mathrm{C}$ and significant mass loss occurred between 400 and $500^{\circ} \mathrm{C}$. Consisting with the literature, this stage indicates the rapid degradation of norbornene chains in the copolymer matrix [46]. In Table $2, T_{\mathrm{d} 5}$ and $T_{\mathrm{d} 10}$ indicate the onset degradation temperatures and $T_{\mathrm{d} 50}$ is the mid-

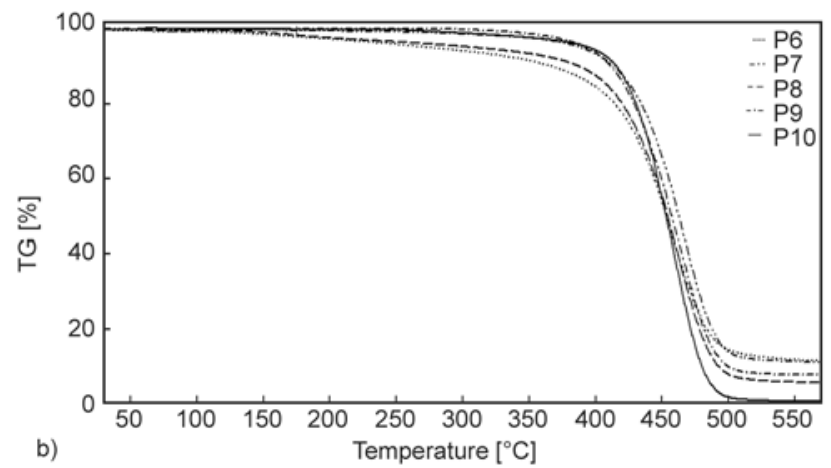

Figure 4. The comparative curves for thermal decomposition of polyHIPEs obtained from TGA: P1-P5 (a) and P6-P10 (b) 

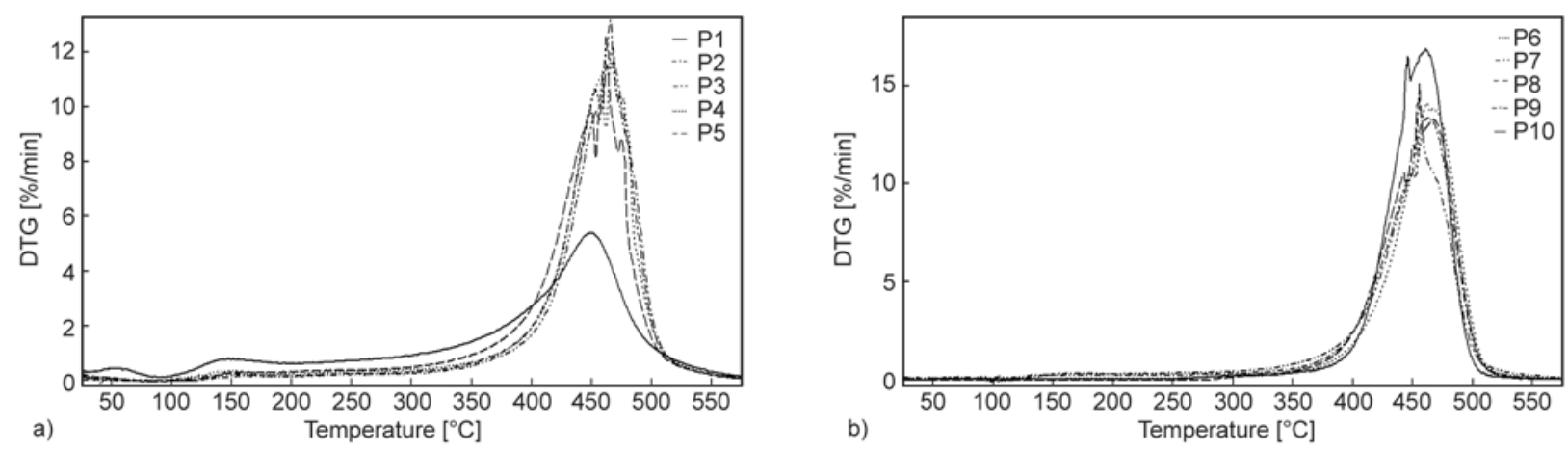

Figure 5. The comparative DTG thermograms of the resulting polyHIPEs: P1-P5 (a) and P6-P10 (b)

point degradation temperature. As shown in Table 2, the increases of the onset degradation temperatures $\left(T_{\mathrm{d} 5}, T_{\mathrm{d} 10}\right)$ and as well as the midpoint degradation temperature $\left(T_{\mathrm{d} 50}\right)$ indicated enhanced thermal stability of poly(DCPD/ NBE) copolymers (P2 to P10) compared with polyDCPD homopolymer (P1).

On the other hand, the copolymerisation of increasing NBE amounts caused an increase of the maximum degradation rate. Table 2 indicates that as well as the maximum degradation temperature increased slightly, the increase of the maximum degradation rate was more remarkable. As compared with the polyDCPD matrix the maximum degradation rate was increased up to $11.5 \%$ for the poly(DCPD/ NBE) copolymers. Accordingly, there is also a significant deterioration of $97.9 \%$ lower char yield than polyDCPD matrix. TGA analyses confirm that NBE amount has a remarkable influence on the degradation behaviour. In comparison with the polyDCPD matrix, polymer backbones decomposed more rapidly at considerably high temperatures for poly (DCPD/NBE) copolymers. This may be explained by the fact that NBE and DCPD units possess different structures and degradation of poly(DCPD/NBE) copolymers requires different energy to occur.

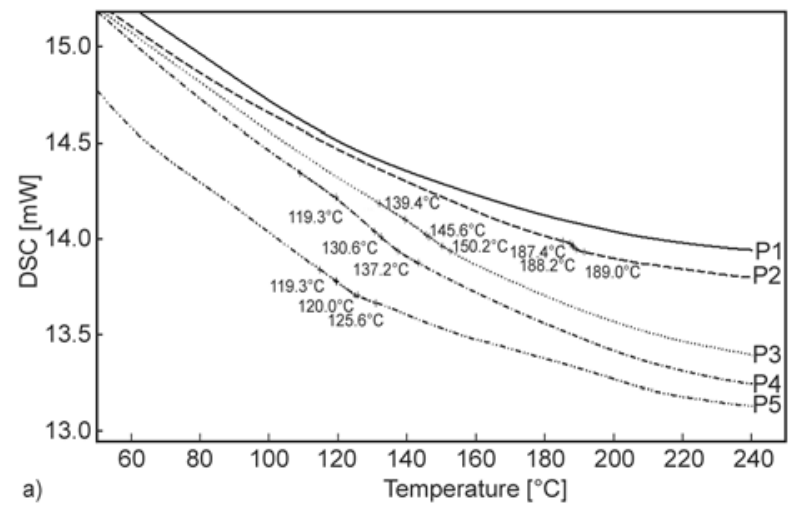

It is known from the literature the $T_{\mathrm{g}}$ value of polyDCPD is usually ranged between 140 and $160^{\circ} \mathrm{C}$, depending on the amount of crosslinked units [47]. However, incorporation of a comonomer into polyDCPD leads to change in glass transition temparature values depending on the nature of the comonomer. The effect of polymer backbone chemistry onto glass transitions of the polyDCPD homopolymer and the resulting copolymers was examined by DSC. The curves obtained from DSC are presented in Figure 6. However we didn't observe any thermal transition for pure polyDCPD matrix (P1) most probably due to the highly cross-linked structure. In all cases of copolymers DSC curves showed only one single glass transition. Consequently, it was confirmed that no phase separated blocks of the mononers were built. By copolymerisation with norbornene, copolymers with glass transition temperatures between 61 and $188^{\circ} \mathrm{C}$ were obtained. With increasing the content of NBE the $T_{\mathrm{g}}$ values of the copolymers were gradually decreased. In particular, $127^{\circ} \mathrm{C}$ decrease in $T_{\mathrm{g}}$ was observed for the copolymer prepared by incorporating $90 \mathrm{~mol} \%$ of NBE (P10) as compared to copolymer sample having $10 \mathrm{~mol} \%$ of NBE (P2). The decrease in the $T_{\mathrm{g}}$ can be explained by the presence

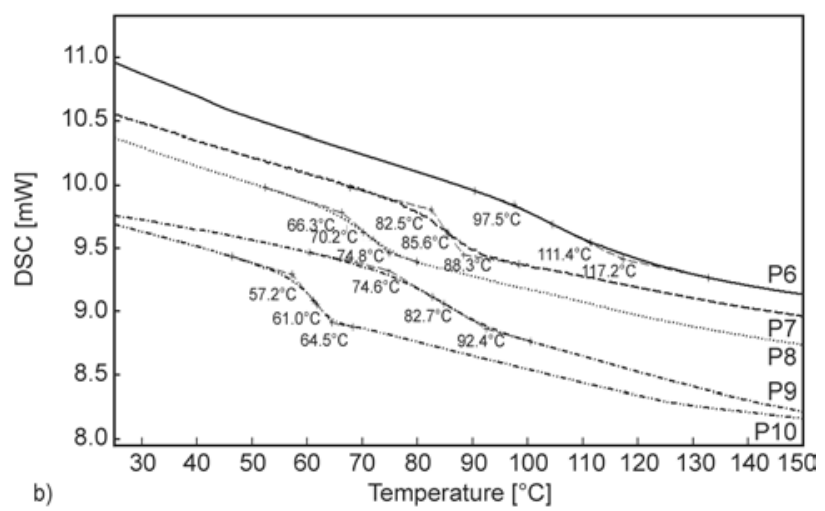

Figure 6. The comparative DSC curves of polyHIPEs: P1-P5 (a) and P6-P10 (b) 
of NBE units in the resulting copolymers. It is known from the literature that $T_{\mathrm{g}}$ of polyNBE range between 20 and $40^{\circ} \mathrm{C}$ [48]. Consequently, the increase in NBE quantity leads to increased flexibility in the polymer backbone and decreased glass transition temperature $\left(T_{\mathrm{g}}\right)$.

\section{Conclusions}

In this paper, we have demonstrated the effect of using a comonomer on the properties of dicyclopentadiene polyHIPEs. Since norbornene can be crosslinked via ROMP and possesses only one double bond, norbornene was used as comonomer. The effect of monomer composition on morphological, mechanical and thermal properties was explored by varying the norbornene composition in HIPEs. By incorporating norbornene into the polymer matrix polyHIPEs exhibited enhanced thermal properties without compromising the morphological features. Moreover, it was found that as compared with the pure polyDCPD matrix addition of $50 \mathrm{~mol} \%$ of NBE into the polymer matrix increases the compression modulus and compressive strength ca. 55\% and ca. $73 \%$, respectively. On the other hand, incorporation of a comonomer into the polymer matrix and its amount has a remarkable effect on the thermal degradation behavior. The onset degradation temperatures were found to increase significantly with the increasing amount of comonomer. Moreover, as compared with the pure polyDCPD matrix, polymer backbones decomposed more rapidly at considerably higher temperatures.

\section{References}

[1] Kimmins S. D., Cameron N. R.: Functional porous polymers by emulsion templating: Recent advances. Advanced Functional Materials, 21, 221-225 (2011). DOI: $10.1002 / \mathrm{adfm} .201001330$

[2] Silverstein M. S.: PolyHIPEs: Recent advances in emulsion-templated porous polymers. Progress in Polymer Science, 39, 199-234 (2014).

DOI: $10.1016 /$ j.progpolymsci.2013.07.003

[3] Tebboth M., Menner A., Kogelbauer A., Bismarck A.: Polymerised high internal phase emulsions for fluid separation applications. Current Opinion in Chemical Engineering, 4, 114-120 (2014).

DOI: $10.1016 /$ j.coche.2014.03.001

[4] Pulko I., Krajnc P.: High internal phase emulsion templating - A path to hierarchically porous functional polymers. Macromolecular Rapid Communications, 33, 1731-1746 (2012).

DOI: $\underline{10.1002 / \text { marc. } 201200393}$
[5] Bartl H., von Bonin W.: Über die polymerisation in umgekehrter emulsion. Die Makromolekulare Chemie, 57, 74-95 (1962).

DOI: $10.1002 /$ macp.1962.020570105

[6] Bartl H., von Bonin W.: Über die polymerisation in umgekehrter emulsion. II. Die Makromolekulare Chemie, 66, 151-156 (1963).

DOI: $10.1002 / \mathrm{macp} .1963 .020660115$

[7] Lissant K. J., Peace B. W., Wu S. H., Mayhan K. G.: Structure of high-internal-phase-ratio emulsions. Journal of Colloid and Interface Science, 47, 416-423 (1974).

DOI: 10.1016/0021-9797(74)90273-2

[8] Lissant K. J., Mayhan K. G.: A study of medium and high internal phase ratio water/polymer emulsions. Journal of Colloid and Interface Science, 42, 201-208 (1973).

DOI: 10.1016/0021-9797(73)90025-8

[9] Lissant K. J.: Emulsions and emulsion technology. Marcel Dekker, New York (1984).

[10] Cameron N. R., Sherrington D. C., Ando I., Kurosu H.: Chemical modification of monolithic poly(styrenedivinylbenzene) polyHIPE ${ }^{\circledR}$ materials. Journal of Materials Chemistry, 6, 719-726 (1996).

DOI: $10.1039 /$ JM9960600719

[11] Mercier A., Deleuze H., Mondain-Monval O.: Preparation and functionalization of (vinyl)polystyrene polyHIPE $^{\circledR}$.: Short routes to binding functional groups through a dimethylene spacer. Reactive and Functional Polymers, 46, 67-79 (2000).

DOI: 10.1016/S1381-5148(00)00040-7

[12] Barbetta A., Cameron N. R., Cooper S. J.: High internal phase emulsions (HIPEs) containing divinylbenzene and 4-vinylbenzyl chloride and the morphology of the resulting polyHIPE materials. Chemical Communications, 2000, 221-222 (2000).

DOI: $10.1039 / \mathrm{A} 909060 \mathrm{~F}$

[13] Štefanec D., Krajnc P.: 4-vinylbenzyl chloride based porous spherical polymer supports derived from waterin-oil-in-water emulsions. Reactive and Functional Polymers, 65, 37-45 (2005).

DOI: 10.1016/j.reactfunctpolym.2005.01.007

[14] Kovaćić S., Krajnc P.: Macroporous monolithic poly(4-vinylbenzyl chloride) columns for organic synthesis facilitation by in situ polymerization of high internal phase emulsions. Journal of Polymer Science Part A: Polymer Chemistry, 47, 6726-6734 (2009). DOI: $10.1002 /$ pola.23732

[15] Krajnc P., Štefanec D., Brown J. F., Cameron N. R.: Aryl acrylate based high-internal-phase emulsions as precursors for reactive monolithic polymer supports. Journal of Polymer Science Part A: Polymer Chemistry, 43, 296-303 (2005). DOI: $10.1002 /$ pola.20501 
[16] Kovačič S., Štefanec D., Krajnc P.: Highly porous open-cellular monoliths from 2-hydroxyethyl methacrylate based high internal phase emulsions (HIPEs): Preparation and void size tuning. Macromolecules, 40, 8056-8060 (2007).

DOI: $10.1021 / \mathrm{ma} 071380 \mathrm{c}$

[17] Zhang H., Cooper A. I.: Synthesis of monodisperse emulsion-templated polymer beads by oil-in-water-inoil $(\mathrm{O} / \mathrm{W} / \mathrm{O})$ sedimentation polymerization. Chemistry of Materials, 14, 4017-4020 (2002).

DOI: $10.1021 / \mathrm{cm} 0206643$

[18] Pulko I., Smrekar V., Podgornik A., Krajnc P.: Emulsion templated open porous membranes for protein purification. Journal of Chromatography A, 1218, 2396-2401 (2011).

DOI: $10.1016 /$ j.chroma.2010.11.069

[19] Barbetta A., Dentini M., Leandri L., Ferraris G., Coletta A., Bernabei M.: Synthesis and characterization of porous glycidylmethacrylate-divinylbenzene monoliths using the high internal phase emulsion approach. Reactive and Functional Polymers, 69, 724-736 (2009). DOI: 10.1016/j.reactfunctpolym.2009.05.007

[20] Yao C., Qi L., Jia H., Xin P., Yang G., Chen Y.: A novel glycidyl methacrylate-based monolith with sub-micron skeletons and well-defined macropores. Journal of Materials Chemistry, 19, 767-772 (2009).

DOI: 10.1039/B816712E

[21] Krajnc P., Štefanec D., Pulko I.: Acrylic acid 'reversed' polyHIPEs. Macromolecular Rapid Communications, 26, 1289-1293 (2005).

DOI: $10.1002 /$ marc. 200500353

[22] Lovelady E., Kimmins S. D., Wu J., Cameron N. R.: Preparation of emulsion-templated porous polymers using thiol-ene and thiol-yne chemistry. Polymer Chemistry, 2, 559-562 (2011).

DOI: $10.1039 /$ C0PY00374C

[23] Caldwell S., Johnson D. W., Didsbury M. P., Murray B. A., Wu J. J., Przyborski S. A., Cameron N. R.: Degradable emulsion-templated scaffolds for tissue engineering from thiol-ene photopolymerisation. Soft Matter, 8, 10344-10351 (2012). DOI: $10.1039 / \mathrm{C} 2 \mathrm{SM} 26250 \mathrm{~A}$

[24] Sergent B., Birot M., Deleuze H.: Preparation of thiolene porous polymers by emulsion templating. Reactive and Functional Polymers, 72, 962-966 (2012). DOI: $10.1016 /$ j.reactfunctpolym.2012.02.011

[25] Sušec M., Ligon S. C., Stampfl J., Liska R., Krajnc P.: Hierarchically porous materials from layer-by-layer photopolymerization of high internal phase emulsions. Macromolecular Rapid Communications, 34, 938-943 (2013).

DOI: $10.1002 /$ marc. 201300016

[26] Johnson D. W., Sherborne C., Didsbury M. P., Pateman C., Cameron N. R., Claeyssens F.: Macrostructuring of emulsion-templated porous polymers by 3D laser patterning. Advanced Materials, 25, 3178-3181 (2013). DOI: $10.1002 / \mathrm{adma} .201300552$
[27] Deleuze H., Faivre R., Herroguez V.: Preparation and functionalisation of emulsion-derived microcellular polymeric foams (polyHIPEs) by ring-opening metathesis polymerisation (ROMP). Chemical Communications, 2002, 2822-2823 (2002).

DOI: $10.1039 / \mathrm{B} 208832 \mathrm{~K}$

[28] Benmachou K., Deleuze H., Herroguez V.: Ring opening polymerisation of highly concentrated inverse emulsions to obtain microcellular foams. Reactive and Functional Polymers, 55, 211-217 (2003). DOI: $10.1016 / \mathrm{S} 1381-5148(02) 00248-1$

[29] Kovačič S., Krajnc P., Slugovc C.: Inherently reactive polyHIPE material from dicyclopentadiene. Chemical Communications, 46, 7504-7506 (2010).

DOI: 10.1039/C0CC02610G

[30] Kovačič S., Jeřábek K., Krajnc P., Slugovc C.: Ring opening metathesis polymerisation of emulsion templated dicyclopentadiene giving open porous materials with excellent mechanical properties. Polymer Chemistry, 3, 325-328 (2012).

DOI: $10.1039 / \mathrm{C} 2 \mathrm{PY} 00518 \mathrm{~B}$

[31] Kovačič S., Kren H., Krajnc P., Koller S., Slugove C.: The use of an emulsion templated microcellular poly (dicyclopentadiene-co-norbornene) membrane as a separator in lithium-ion batteries. Macromolecular Rapid Communications, 34, 581-587 (2013).

DOI: $10.1002 /$ marc. 201200754

[32] Kovačič S., Preishuber-Pflügl F., Slugovc C.: Macroporous polyolefin membranes from dicyclopentadiene high internal phase emulsions: Preparation and morphology tuning. Macromolecular Materials and Engineering, 299, 843-850 (2014).

DOI: $10.1002 /$ mame. 201300400

[33] Krajnc P., Leber N., Štefanec D., Kontrec S., Podgornik A.: Preparation and characterisation of poly (high internal phase emulsion) methacrylate monoliths and their application as separation media. Journal of Chromatography A, 1065, 69-73 (2005).

DOI: $10.1016 /$ j.chroma.2004.10.051

[34] Moine L., Deleuze H., Maillard B.: Preparation of high loading polyHIPE monoliths as scavengers for organic chemistry. Tetrahedron Letters, 44, 7813-7816 (2003). DOI: $10.1016 / \mathrm{j}$.tetlet.2003.08.051

[35] Christenson E. M., Soofi W., Holm J. L., Cameron N. R., Mikos A. G.: Biodegradable fumarate-based polyHIPES as tissue engineering scaffolds. Biomacromolecules, 8, 3806-3814 (2007).

DOI: $10.1021 / \mathrm{bm} 7007235$

[36] Krajnc P., Leber N., Brown J. F., Cameron N. R.: Hydroxy-derivatised emulsion templated porous polymers (polyHIPEs): Versatile supports for solid and solution phase organic synthesis. Reactive and Functional Polymers, 66, 81-91 (2006).

DOI: $10.1016 /$ j.reactfunctpolym.2005.07.023 
[37] Mert E. H., Kaya M. A., Yıldırım H.: Preparation and characterization of polyester-glycidyl methacrylate polyHIPE monoliths to use in heavy metal removal. Designed Monomers and Polymers, 15, 113-126 (2012). DOI: $10.1163 / 156855511 X 615001$

[38] Mert E. H., Yıldırım H., Üzümcü A. T., Kavas H.: Synthesis and characterization of magnetic polyHIPEs with humic acid surface modified magnetic iron oxide nanoparticles. Reactive and Functional Polymers, 73, 175-181 (2013).

DOI: 10.1016/j.reactfunctpolym.2012.09.005

[39] Tunç Y., Gölgelioğlu Ç., Hasirci N., Ulubayram K., Tuncel A.: Acrylic-based high internal phase emulsion polymeric monolith for capillary electrochromatography. Journal of Chromatography A, 1217, 1654-1659 (2010).

DOI: 10.1016/j.chroma.2010.01.020

[40] Menner A., Salgueiro M., Shaffer M. S. P., Bismarck A.: Nanocomposite foams obtained by polymerization of high internal phase emulsions. Journal of Polymer Science Part A: Polymer Chemistry, 46, 5708-5714 (2008). DOI: $10.1002 /$ pola.22878

[41] Kovačič S., Matsko N. B., Jerabek K., Krajnc P., Slugove C.: On the mechanical properties of HIPE templated macroporous poly(dicyclopentadiene) prepared with low surfactant amounts. Journal of Materials Chemistry A, 1, 487-490 (2013).

DOI: $10.1039 / \mathrm{C} 2 \mathrm{TA} 00546 \mathrm{H}$

[42] Kovačič S.: Ring opening metathesis polymerisation (ROMP) as a tool for polyHIPES with extraordinary mechanical properties. Acta Chimica Slovenica, 60, 448-454 (2013).
[43] Wu R., Menner A., Bismarck A.: Tough interconnected polymerized medium and high internal phase emulsions reinforced by silica particles. Journal of Polymer Science Part A: Polymer Chemistry, 48, 1979-1989 (2010).

DOI: $10.1002 /$ pola.23965

[44] Ikem V. O., Menner A., Bismarck A.: High-porosity macroporous polymers synthesized from titania-particle-stabilized medium and high internal phase emulsions. Langmuir, 26, 8836-8841 (2010). DOI: $10.1021 / 1 a 9046066$

[45] Barbetta A., Cameron N. R.: Morphology and surface area of emulsion-derived (polyHIPE) solid foams prepared with oil-phase soluble porogenic solvents: Span 80 as surfactant. Macromolecules, 37, 3188-3201 (2004). DOI: $10.1021 / \mathrm{ma} 0359436$

[46] Carvalho Jr. V. P., Ferraz C. P., Lima-Neto B. S.: Tailored norbornene-based copolymer with systematic variation of norbornadiene as a crosslinker obtained via ROMP with alternative amine Ru catalysts. European Polymer Journal, 48, 341-349 (2012). DOI: $10.1016 /$ j.eurpolymj.2011.11.011

[47] Morbelli L., Eder E., Preishuber-Pflügl P., Stelzer F.: Copolymerizations between cyclic olefins and norbornene lactone. Journal of Molecular Catalysis A: Chemical, 160, 45-51 (2000). DOI: $10.1016 / \mathrm{S} 1381-1169(00) 00231-4$

[48] Carvalho Jr. V. P., Ferraz C. P., Lima-Neto B. S.: Electronic synergism in $\left[\mathrm{RuCl}_{2}\left(\mathrm{PPh}_{3}\right)_{2}(\right.$ amine $\left.)\right]$ complexes differing the reactivity for ROMP of norbornene and norbornadiene. Journal of Molecular Catalysis A: Chemical, 333, 46-53 (2010). DOI: $10.1016 /$ j.molcata.2010.09.015 